\title{
Introduction: Democratic Institutions for a New Europe
}

\section{Gerald Schneider}

University of Konstanz

\section{Daniel Verdier}

Ohio State University

Institutional reforms have up to now always preceded or immediately followed any major enlargement round of the European Union, fueling functionalist hopes that the organization will ultimately become a nation-state. Yet the prolonged failure to redistribute power effectively between member states, the Commission, the Parliament, and the European Court of Justice means that these past successes have also stretched the size and the institutions of the Union to the limit. Despite its minimalist results, the Treaty of Nice was not yet in force in the fall of 2002, causing the European Union to face considerable problems in dealing adequately with the Eastern enlargement, allegedly the greatest challenge it has ever faced.

By admitting up to 12 new members during the next decade, not only will the European Union increase in size, but, what is more troubling, heterogeneity among the member states will grow to an unprecedented degree. Excessive divergence could become a problem far beyond Groucho Marx's famous quip: 'I sent the club a wire stating: "Please accept my resignation." I don't want to belong to any club that will accept me as a member.' ${ }^{1}$ The theory of collective action suggests that the provision of the collective good, be it a pure public good or a club good, becomes more cumbersome the more actors contribute to it and the more dissimilar they are (Sandler, 1992). Although increased trade between the old and new member states might offset some of these negative aspects (Schneider, 2002), this might not be enough to bind the members of an increasingly heterogeneous club together.

Only a proper set of institutions can guarantee that the European Union will provide the collective goods that the member states expect it to deliver. The ratification pains felt over the Treaty of Nice are, however, an indication 
that the current member states have difficulties in adapting the 'rules of the game' to an enlarged European Union. Without downplaying the importance of the European Convention, we find it hard to imagine that the member states will easily agree on a new set of rules, assuming that the governmentmandated constitution builders do innovate at all.

Most of the complications encountered in reforming the institutions of the EU arise because negotiators can easily anticipate who will gain or lose from any proposed change. Recurrent fighting over the voting weights in the Council of Ministers and endless debates over the composition of the European Commission suggest that even minimal reform provokes fierce resistance. The severity of these struggles demonstrates that the reforms on treaty changes do not take place behind a Rawlsian 'veil of ignorance.' On the contrary, most member states know in advance how many subsidies and transfers they will lose once they have to divide an only marginally larger pie among more players.

The difficulties in finding new arrangements make it necessary to understand the current functioning of existing rules and how enlargement might alter them. Most studies on enlargement emphasize the 'demand' for membership and whether or not certain member states are fit to join the European Union. Institutional analyses that carefully examine the present and future impact of the power distribution, horizontally across legislating bodies and vertically between the Union and the national governments, are clearly missing. This special issue is a first attempt to close this gap. It brings together several cutting-edge lines of research, centering on key institutional arrangements. All contributors offer conjectures about the ways in which current institutions function and how they might evolve in the future. The Forum section also features a useful review by Simon Hug of the formal work on federalism, which is a valuable starting point for the study of European institutions.

The contributors of the essays ask two main questions. First, a normative question: How representative is the European Union and how legitimate are its decisions? Second, a positive question: How much power does a particular actor possess and how efficient are the existing decision-making rules in the old (and possibly also in the new) European Union? In this brief introductory essay, we first introduce each contribution and then summarize the open research questions.

\section{About the articles in this issue}

The discourse on the so-called democratic deficit has dominated academic research on the European Union in the past few years. Although it is hard to 
assess this massive literature, most papers and books have focused, in one way or the other, on what Easton $(1953,1965)$ called the 'input' and 'output' legitimacy of political institutions. A political institution can garner public support through its institutions and decision-making processes, but it can also manipulate its popularity through the policies it produces.

Most observers maintain that one of the foremost problems is the lack of a European demos, a population that sufficiently identifies with the European Union (e.g. Scharpf, 1999). Sánchez-Cuenca (2000), in contrast, contends that citizens merely compare the performance of the European Union with the performance of other political institutions, notably their national government. If we assess the democratic deficit in this way, much of the concern about the absence of a European citizenry seems exaggerated. The contribution by Christophe Crombez to this issue adds to this moderate assessment. He focuses on a key and largely understudied aspect of democracy in the European Union, namely how representative policies are of the median voter's substantive preferences. He shows that co-decision procedures are representative and will remain so under the envisioned enlargement. We could add to this analysis that even decisions made purely in the Council of Ministers are fairly representative if we take into account that the participating ministers are representatives of elected governments. The only problem that continues to harm the legitimacy of the EU at this level is, in Crombez's view, the limited transparency of the deliberations within the Council of Ministers, making monitoring by informed citizens a difficult task.

The contribution by Ken Kollman similarly argues that a properly managed Council of Ministers may be more efficient than many observers contend. This contribution offers what we believe to be the first systematic evaluation of the rotating presidency. Simulating its functioning, Kollman seeks to determine whether this unique institutional setup helps or hinders the adoption of socially optimal policies. The result demonstrates that the rotating presidency is a convincing mechanism, at least in the present size of the European Union - it facilitates the 'search for good policies.' However, Kollman argues that rotating the presidency on a half-year basis would be unsustainable in an enlarged EU, raising the danger of admitting states with governments that opt for socially suboptimal policies.

Relying on different analytic tools, the short contribution by Hannu Nurmi and Madeleine Hosli also envisions institutional change. The authors argue that an enlarged Council of Ministers will no longer be able to resort to informal voting, but instead will be forced to confront the standard paradoxes that come with formal voting - the danger of voting cycles and the threat of what the social choice literature calls the 'no-show paradox.' The noshow paradox is the possibility that a participant might be better off by 
abstaining from a decision than by formally taking part in it. Nurmi and Hosli survey a range of voting techniques, sorting them according to their relative capacity to eschew one or both paradoxes.

The article by Fabio Franchino and Anne Rahming touches upon a policy area in which policy-making in the Council can malfunction in the absence of external control. Although the fisheries policy is almost as important as agricultural policy-making, we possess little systematic knowledge on how the Council, the Commission, and domestic stakeholders are able to affect the policy choices of the fishing nations. The authors argue that specialized councils are composed of preference outliers, who are more supportive of producers than of popular concerns. Strengthening the European Commission, though probably not the best way of democratizing the European Union, is one solution that the Council can avail itself of to deal with the problems created by its own decision-making.

It is never easy to understand how an institution functions at the moment of its creation; it is even more difficult to say how it may develop over time, especially whether and how it will become legitimate. Clifford Carrubba tackles this difficult theoretical question in his study of the European Court of Justice. He offers a dynamic model that allows him to account for the evolution of the Court from being an intergovernmental agent, capable of ruling only against governments likely to be retaliated against by other governments, to a legitimate institution, capable of enforcing compliance on its own. Carrubba's sophisticated model operates on minimalist assumptions, not requiring citizens to hold any prior belief that their government should comply with European law or court decisions. In the mind of the people, the Court starts like any other strategic player. The only ingredient required to trigger the legitimation mechanism, interestingly enough, is a large number of minor violations, sufficiently minor to make other governments' threat of retaliation credible. The mechanism identified by Carrubba works in the long run. With respect to the immediate future, the future that is relevant to enlargement, Carrubba is able to predict that the ability of the Court to rule against new entrant governments will strictly depend on the popularity of the EU with each government's citizenry.

\section{Future research agenda}

The academic discussion on European enlargement is for obvious reasons heavily influenced by current events. We will probably observe a move from negotiation analyses to policy studies over the coming years. Also, whereas 
the first generation of studies assessed the pros and cons of enlargement in a rather general way, present studies are more detailed and empirically grounded. Once some of the 'new entrants' are eventually admitted to the organization, we will be able to support our speculations over the impact of enlargement with real data. One issue that will become particularly important is the question of how European Union decisions are implemented in the new (but also in the old) member states. To paraphrase Pressman and Wildavsky's (1973) pioneering contribution, 'Implementation, or How Great Expectations in Brussels Are Dashed in Helsinki, Finland' (or Ljubljana, Slovenia, for example) is likely to become one of the most interesting questions for EU research. The entry of the applicant states will also provide researchers with the necessary data to assess the institutional consequences of widening - namely, the possibility that the European Union will less often be able to bind governments or that decision-making will be less efficient. Although the papers in this issue do not address these questions, they open the way toward the comparative institutional analysis of decision-making cycles and the danger of gridlock that every complex organization faces.

\section{Notes}

The papers collected in this special issue were presented for the first time at the conference on 'Democratic Institutions for a Large European Union', at the Robert Schuman Centre for Advanced Studies of the European University Institute, in Florence, Italy, 13-15 December 2001. Besides the contributors, we would like to thank the discussants - David Epstein, Sharyn O'Halloran, Ulrich Sedelmeier, Angela Liberatore, and Helen Wallace - and the reviewers for their help in making the articles publishable. We would also like to acknowledge the energy that Ramon Marimon and Josep Colomer invested in getting the project off the ground. The project was made possible by a grant from the European Commission.

1 http://www.groucho-marx.com/ (last consulted on August 30, 2002).

\section{References}

Easton, David (1953) The Political System: An Inquiry into the State of Political Science. New York: Knopf.

Easton, David (1965) A Systems Analysis of Political Life. New York: Wiley.

Pressman, Jeffrey L. and Aaron Wildavsky (1973) Implementation: How Great Expectations in Washington Are Dashed in Oakland. Berkeley: University of California Press.

Sánchez-Cuenca, Ignacio (2000) 'The Political Basis of Support for European Integration', European Union Politics 1(2): 147-72. 
Sandler, Todd (1992) Collective Action. Ann Arbor: University of Michigan Press. Scharpf, Fritz W. (1999) Governing in Europe: Effective and Democratic? Oxford: Oxford University Press.

Schneider, Gerald (2002) 'A Never Ending Success Story? The Dynamics of Widening and Deepening European Integration', in Bernard Steunenberg (ed.) Widening the European Union: The Politics of Institutional Change and Reform, pp. 183-201. London: Routledge.

\section{About the authors}

Gerald Schneider is Professor of Political Science in the Department of Politics and Management, University of Konstanz, 78457 Konstanz, Germany.

Tel: $+497531882608 / 3081$

Fax: +497531882774

E-mail: gerald.schneider@uni-konstanz.de

Daniel Verdier is Associate Professor in the Department of Political Science, The Ohio State University, 2140 Derby Hall, 154 North Oval Mall, Columbus, OH 43210-1373, USA.

Tel: +1614 292-2880

Fax: +1 614 292-1146

E-mail: verdier@osu.edu 